\title{
Literatura e outras linguagens
}

\author{
M aria H elena Cruz Pistori* \\ BRAIT, Beth. São Paulo: Contexto, 2010, 235p.
}

De início, é importante frisar que esta obra de Beth Brait não é um texto teórico. E devemos aqui acrescentar: não é explicitamente um texto teórico. D irigida primeiramente a professores de língua e literatura, aqueles aos quais a sociedade incumbiu de despertar na criança o "gosto pela leitura", também se destina àqueles que simplesmente gostam de ler, que consideram "o texto uma forma de conhecimento, fonte de prazer".

Acostumados que estamos à Beth Brait crítica e ensaísta dos textos científicos, que se dirige aos pares, e àquela dos ensaios mais densos ou dos artigos teóricos (sempre aliados a uma postura prática, é verdade); acostumados, mais especialmente, à autora que tem buscado desvendar os sentidos e a aplicação dos conceitos desenvolvidos pelo Círculo de Bakhtin, escrevendo, por exemplo, "Alteridade, dialogismo, heterogeneidade: nem sempre o outro é o mesmo"1 ou "Interação, gênero e estilo"2, entre outros artigos, e organizando obras que vão na mesma direção, como Bakhtin: conceitos-chave, Bakhtin: outros conceitos-chave, Bakhtin eo Círculo, Bakhtin, dialogi smo e polifonia..., todas publicadas pela editora Contexto; ou textos propositivos de uma análise dialógica do dis curso, como "U ma perspectiva dialógica de teoria, método e análise"3 ou "M emória, linguagens, construção de sentidos"4; ou compondo artigos que buscam ainda, mais recentemente, criar um aparato teórico-dialógico para a análise do verbo-visual, como "A palavra mandioca do verbal ao verbo-visual" ${ }^{-}$, acos-

\footnotetext{
* Pós-doutoranda em Linguística aplicada e estudos da linguagem, Pontifícia U niversidade Católica de São Paulo / Fundação de Amparo à Pesquisa do Estado de São Paulo (Proc. 2009/16902-8), SP, Brasil. mhcpist@uol.com.br

1. In: Brait, B. (O rg.) Estudos enunciativos no Brasil: histórias e perspectivas. Campinas, SP: Pontes; São Paulo: Fapesp, 2001.

2. Inserido em Preti, D. (O rg.). Interação na fala e na escrita. São Paulo: Humanitas/FFLCH/USP, 2002. p. 125-157.

3. Gragoatá, Niterói, n. 20, p. 47-62, 1. sem. 2006.

4. In: Lara, G. M. P. et alii (O rg.). Análises do discurso hoje. Rio de Janeiro: N ova Fronteira, 2008, pp.115-132. V. 2.

5. In: Bakhtiniana. Revista de Estudos do Discurso. São Paulo, v. 1, n. 1, p.142-160, 1. sem. 2009. D isponível em: http://revistas.pucsp.br/index.php/bakhtiniana/article/view/3004/1935. Acesso em: 19 set. 2009.
} 
tumados a essa autora, o livro surpreendenos. É o estilo simples, descontraído e agradável que torna possível a fruição da obra por diferentes leitores, chegando mesmo aos especialistas da academia. Sim, pois tal leveza de estilo permite que a profundidade do texto alcance destinatários diversos, presentes e interpelados ao longo de toda a obra, instados a dial ogar com ela e com os diferentes textos e autores com quem Brait nos coloca em contato.

De que trata a obra? 0 título, Literatura e outras linguagens, já nos dá 0 mote presente ao longo de todos os capítulos: será o enfoque de língua e literatura como "parceria inquestionável" e necessária nos estudos da linguagem. Essa parceria será atestada por meio de textos e depoimentos de escritores, de linguistas, de pesquisadores da linguagem e especialistas da literatura, que mostram a indissolúvel união existente entre ambas "nas estantes da vida". D essa forma, nosso discurso na vida e na arte apresenta-se na obra por meio das vozes postas a dialogar acerca da literatura, da língua, das diferentes linguagens, em suas diferentes dimensões.

0 livro está organizado em sete unidades. $\mathrm{N}$ a primeira, Língua e literatura: saber e sabor, poderíamos dizer que o início é teórico, dado que a autora se propõe tematizar a "relação constitutiva língua-literatura" por meio de Roman Jakobson, o "poeta da linguística", e Valentin Voloshinov, o linguista do Círculo bakhtiniano. Se encontramos o saber nos excertos dos teóricos e nos comentários acerca da articulação língua e literatura em suas produções, o sabor da unidade, assim como de toda a obra, também se deve a expressões como a que apresenta Jakobson como "um linguista para ninguém botar defeito". Complementando a unidade, os depoimentos de linguistas - Dominique $M$ aingueneau, Carlos Alberto Faraco, Sírio Possenti (“... o que me interessa mesmo é uma boa história...") e Luiz Carlos Travaglia - especialmente produzidos para esta obra, tornam-na mais saborosa.

As unidades seguintes têm praticamente a mesma estrutura: iniciam-se com um debate acerca do tema em questão, dialogando com textos e autores que dele trataram, para então apresentar textos e depoimentos inéditos de conhecidos autores. $\mathrm{N}$ a segunda unidade, a questão proposta é o modo como "escritores enfrentam e mostram a língua". Percebemos nela como o material e a forma se aliam ao conteúdo no fazer literário, com trechos de Graciliano Ramos, Guimarães Rosa e Roberto G omes, escritor contemporâneo que também contribui com um depoimento especial para a obra ("No colégio, o tédio. A última flor do Lácio inculta e bela. [...] Era o fecho: além dos botecos, estudar literatura no colégio virara uma tremenda farra").

$\mathrm{N}$ a terceira unidade, a questão da relação entre língua, literatura e identidades é debatida. N ovamente textos muito bem selecionados para refletirmos e dial ogarmos acerca da questão. Trechos de Alencar, M ário de Andrade, 0 swald, 
lado a lado com o "Samba do approach" e "Kid Vinil", de Zeca Baleiro, e com a riqueza literária do texto de uma senhora do povo, a "senhora de Sairé". A seguir, excertos de Luiz Alfredo Garcia-Roza dialogando com o "Poema tirado de uma notícia de jornal", de Bandeira; e ainda, para exemplificar a "multiplicidade de vozes que caracterizam uma época" - a contemporânea -, um trecho de Patrícia M elo e o depoimento de M irna Pinski. Vamo-nos dando conta da sensibilidade linguístico-literária da autora por meio da escolha dos textos, dos comentários e das análises que parecem tão simples de compreender, mas que escondem uma profundidade teórica conseguida apenas graças à ampla experiência profissional e à formação acadêmica exemplar. U m depoimento de Brait, revelando-se aluna de Francisco da Silva Borba no curso ginasial, em Itapetininga, apresenta o estudo por ele empreendido sobre uma "visão linguística" da literatura como registro. 0 capítulo encerra-se com 0 depoimento de mais um linguista de peso, D ino Preti, falando de seu trabalho com a literatura como registro da língua oral.

$\mathrm{N}$ as unidades seguintes, a preocupação com 0 ensino de língua e com a construção de sujeitos leitores, cidadãos: "Aprender e ensinar língua portuguesa (ou qualquer outra língua) não é simples. Ao contrário: é muito difícil. $\mathrm{N}$ ão existem fórmulas mágicas e muito menos receitas infalíveis que durem para sempre e se adaptem a qualquer época, grupo, sociedade". N o debate sobre a questão, novamente poetas, como Leminski, Augusto de Campos, Carlos Vogt ("poetalinguista"), I gnácio de Loyola Brandão; e ainda, M aria H elena de M oura $\mathrm{N}$ eves (a busca de nosso lugar na vida: "N a tentativa de resposta, só vejo um lugar onde possamos encontrar companhia e orientação para essa busca: as 'invenções' dos poetas que, às vezes, roubando vida a nós mesmos, deixamos dormir em nossas estantes"); M arisa Lajolo, que destaca o encanto escolar com o ensino da "análise lógica”; e Regina Zilberman (“...o que melhor apreendi com a gramática foi... literatura").

A seguir, ao tratar da "fronteira dos sentidos", o destaque será a relação arte/ vida/memória, exemplificada em textos que colocam "em pé o vivido, 0 imaginado e a mistura das duas coisas por meio da linguagem". M ais uma vez, a seleção é primorosa, e aqui vale lembrar: cada trecho citado evoca o todo de que faz parte. A apresentação é o momento em que a autora não se esquece de alertar e seduzir o leitor para a leitura da obra completa, o que faz, realmente, desde a primeira unidade. D ialogam ali Cristóvão Tezza - "N enhum trecho, isoladamente, poderá nos dar a dimensão desse magnífico romance"; Chico Buarque - "Trechos extraídos de diferentes momentos da narrativa estabelecem, de forma clara, as relações entre lembranças, identidade, linguagem, funcionando como uma antessala para a leitura da totalidade do romance"; M ilton $\mathrm{H}$ atoum - "O mistério somente envolverá o leitor que acompanhar toda a 
narrativa..."; Bernardo Carvalho - "Um excerto certamente fará o leitor compreender a qualidade do romance e optar, imediatamente, pela leitura completa da narrativa"; Rubem Fonseca, com trecho da crônica "Exitus letalis". D epoimentos de nossos grandes linguistas atestam o entrelaçamento de suas vidas com a literatura desde a infância: José Luiz Fiorin - “... como andar sem literatura?" e Ingedore Villaça Koch - "... a literatura foi para mim uma companheira constante."

E vale apontar que os depoimentos em geral, destacando motivos que levaram especialistas da linguagem a sua escolha profissional, trazem sempre aspectos que nos identificam a eles: é mais um ponto que certamente seduz 0 leitor, professor ou apreciador de nossa língua e literatura. M ais interessante ainda é observar como várias vezes o encanto com a gramática levou o especialista ao trabalho com a literatura (caso de M arisa Lajolo) e, outras vezes, 0 encanto com a literatura levou-os ao trabalho com a língua (caso de Fiorin e M aria H elena M oura N eves, entre outros). A "parceria inquestionável" língua eliteratura movenos - professores de língua - ao trabalho com a(s) linguagem(s).

A sexta unidade tem a canção como destaque: as letras de C aetano, Luiz Tatit, Sandra Perez e Luiz Tatit e Juraildes da Cruz são analisadas para que possamos apreciar, compreender e conhecer variedades e particularidades da língua portuguesa (ainda é preciso ouvir as canções, sempre nos lembra Brait). Termina poeticamente com uma montagem do escritor angolano 0 ndjaki, especialmente para a obra: Da língua que se fala à língua que se sonha (autocomentários em quatro andamentos): "Escrevo para celebrar a liberdade que a minha língua permite. E para ser feliz".

É na última unidade que tem lugar o exame das "tramas verbo-visuais da linguagem", por meio de finas análises que nos fazem perceber o visual como constitutivo do sentido do todo indissolúvel dos enunciados concretos selecionados. A análise dos textos dá oportunidade para que a autora nos lembre, por exemplo, da necessidade da aplicação não mecânica da noção de gênero, "na medida em que este não é unidade autônoma, mas dependente de aspectos ligados à sua produção, circulação e recepção, tanto no sentido situacional específico como no que diz respeito ao contexto mais amplo".

Finalizando, acreditamos que é justamente a preocupação ética e cognitiva do trabalho com as linguagens que leva Brait a nos apresentar uma obra não explicitamente teórica (a ciência e a vida não têm acabamento, ensina Bakhtin): a "banalização das teorias", diz ela, "transformadas em ferramenta única, não é capaz de formar leitores proficientes em textos". N ão se constituindo numa antologia, no sentido tradicional, a excelência dos textos e excertos selecionados permite que, eventualmente, a obra até possa ser trabal hada como tal: as análises exemplares cultivam o olhar do leitor. E, sobretudo, levam-nos à com- 
preensão do estético em sua ligação com a vida e a ciência, na unidade da cultura humana. $\mathrm{N}$ esse sentido, a bela capa do livro é o primeiro exemplo de um bem tramado enunciado concreto verbo-visual. 